\title{
Practical Design Considerations for Large Marine Structures in South Carolina
}

\author{
Robert E. Dullanty Sr., P.E. \\ Principal Engineer \\ Schneider \& Associates, Inc.
}

\begin{abstract}
Criterion 3 of ABET 2004-2005 Criteria for Accrediting Engineering Programs requires that all engineering programs seeking accreditation manifest that their graduates have an ability to "function on multidisciplinary teams." Students should be able to serve as both a team leader and a contributing member of a design team. This paper presents a case study of two heavy marine structures in the Charleston, South Carolina. Heavy marine structures typically involve large and unusual loads from cranes, ships, and cargo; generally are supported upon weak and sloped soils; and usually require significant design considerations for marine and coastal environments including corrosive conditions. Marine structures provide for excellent classroom case studies because they inherently require multidisciplinary evaluation and site specific engineering solutions.

Introduction

This paper discusses practical design considerations for large marine structures in South Carolina. As examples, it uses two projects from the South Carolina State Ports Authority. The first project is the evaluation and upgrading of container crane rails at the North Charleston, SC, terminal, and the second project is the investigation and evaluation of an existing 1940's era warehouse foundation for use as a new wharf foundation in Charleston, SC.

The South Carolina State Ports Authority operates six waterfront sites that handle containerized cargo, bulk cargo and break-bulk cargo. As a container port, Charleston generally ranks fourth in the U.S. in terms of containerized cargo volume. This is done through four terminal sites located in the Charleston, South Carolina area. The South Carolina State Ports Authority also operates two smaller bulk and break-bulk ports located in Port Royal, South Carolina and Georgetown, South Carolina.

Evaluation and Upgrade of Container Crane Rail Beams at the North Charleston Terminal The South Carolina State Ports Authority (Ports Authority) needed to upgrade container cranes at its facilities and decided to acquire new cranes and relocate several exiting cranes between their various Charleston area terminals. The North Charleston Terminal was slated to have some "middle aged" container cranes relocated to the terminal to replace the Ports Authority's oldest container cranes. These new cranes were faster, reached farther, and of course, imparted higher loads onto the supporting wharf.
\end{abstract}


The North Charleston Terminal's wharf is approximately 2400 feet long and has a "top of wharf" elevation of 12 feet above mean low water. The berths are periodically dredged to a depth approximately 44 feet below mean low water. In general the structure has integral concrete deck and beams supported on concrete piles. Large concrete beams are situated below the container crane rails. These container crane rail beams vary in size, but are generally 4 -feet deep by 2 -feet wide and span 6 to 10 feet between pile supports. The 2400 foot wharf consists of several large sections with the earliest section constructed in the 1950's and various other sections constructed periodically over the next 45 years.

In anticipation of relocating the cranes, the Ports Authority utilized a national marine engineering firm and a local geotechnical firm to analyze the strength of the existing crane beams for the full length of the wharf. This analysis was based upon a visual examination of the crane rail beams, existing drawings, and existing geotechnical data. The results of this analysis provided a summary of the allowable and ultimate strength capacities of the various lengths of the crane rail beams.

After completion of the crane purchasing and relocation plans, the only crane operational change to the North Charleston Terminal was to operate two of the "middle aged" cranes from another location on a section of the $2400-\mathrm{ft}$ wharf located from station $1500-\mathrm{ft}$ to station $2000-\mathrm{ft}$. This section of the wharf was constructed in the 1950's. Comparing the loads from these cranes with the crane beam analysis showed that the waterside crane rail beam required strengthening along the entire 500-foot length, while the landside crane rail beam required strengthening along only $1 / 2$ the 500-foot length, from station 1750 to station 2000. The underside of the waterside crane rail beam was accessible by a small boat below the wharf. However the landside crane rail beam was behind the retaining wall and the underside was not accessible without demolition of either the crane rail beam or the adjacent wharf deck. This lack of accessibility resulted in the repair cost for the landside crane rail beam to be twice as much per foot as the waterside crane rail beam. In summary, the proposal for strengthening the 500-feet of waterside crane rail beam was $\$ 1.5$ million and that for the 250 -feet of the land-side crane rail beam was $\$ 1.5$ million resulting in a total project cost of $\$ 3.0$ million.

Prior to proceeding with the design, the engineering staff questioned why the landside crane rail beam only required strengthening for $1 / 2$ of the 500 -foot length. The only significant change in structure between the two halves was that the piles were embedded, by design, 5 feet less in the section requiring strengthening. A review of known geotechnical data indicated no significant variations to the soil configuration between the two halves. Generally, the supporting soil in this area is stiff clay locally known as the Cooper Marl. At the wharf, the marl is located approximately 33-35 feet below mean low water. With that information, the decision was made to spend approximately $\$ 25,000$ to perform additional detailed geotechnical testing along the 500 -feet of the landside crane rail beam. The geotechnical testing revealed that a "weathered", or slightly weaker, layer of marl existed above the previously estimated marl level. Based upon the additional strength of this weathered layer, the engineers were able to eliminate strengthening of the landside crane rail beam, saving $\$ 1.5$ million. 
The waterside crane rail, however, did require strengthening. The waterside crane rail beam was supported by a pile cap over two hexagonal piles. These pile pairs and cap were located at $71 / 2$ feet on center. Repair entailed installing a pair of piles and a new pile cap to support the beam between each of the existing supports. This meant driving piles only 3 to 4 feet from existing piles. This procedure was complicated by the nature of the Cooper Marl which was also known as a material that did not compress, but rather displaces. Other projects in the area had caused inplace driven piles to move significantly when new piles where driven in nearby proximity to them. In this situation, it was imperative that movement of the existing piles be avoided. The Ports Authority preferred concrete piles for corrosion purposes, but these would have caused high displacement and thereby problems with the adjacent wharf. The proposed solution was to use a composite pile with a steel H-pile tip and a square, prestressed concrete top. The H-pile tip would be driven into the marl with the concrete portion buried until the concrete tip was 5-feet into the marl. At that point, the top of the concrete pile could be cut-off at the desired location. To provide adequate surface area on the H-pile tip and account for potential berth deepening, the H-pile tip was 42-feet long and the 18-inch square concrete portion of the pile was 48-feet long.

Investigation and Evaluation of an Existing 1940's era Warehouse Foundation for Use as a New Wharf Foundation

The existing buildings, numbered 301, 302 and 303, are warehouses located over the water at the Ports Authority's Union Pier Terminal located in Charleston, SC. These are metal framed buildings with wood floors. Buildings 301 and 302 are abandoned, and the wood flooring is in a severely deteriorated condition. Building 303 is currently in use. There were no drawings available on these buildings and it is estimated that they were likely built in the 1940's.

The Ports Authority desired to improve the facility by removing the existing wood floor and constructing a concrete floor that would be able to support a test load of approximately 1,000 pounds per square foot. This project was divided into phases I and II. Phase I would investigate the existing conditions to determine the approximate capacity of the existing foundation system. Phase II would be to proceed with a foundation load testing program to verify the predicted strength of the limited investigation.

Buildings 301, 302 and 303 at the SCSPA's Union Pier Terminal have a foundation system that is concrete above the mud line, except that the last floor support on the landside of Building 302 is timber supported. Investigation and evaluation from the Phase I investigation resulted in the following information and recommendations.

1. The concrete beam members of the existing foundation system were not capable of supporting higher loads. This limitation applies to the beam whether the beam is in a good or deteriorated condition. In good condition, the engineers confirmed the existing live load limit of 250 pounds per square foot. In the current deteriorated condition, however, the beam strength is significantly reduced. For example, at test location B1 below Building 302, the loss of steel stirrups limits the live load capacity to approximately 100 pounds per square foot. This limit may be further reduced for corrosion of the longitudinal rebar. These deteriorated beam conditions exist throughout the foundation system as evidenced by cracking, rust stains and the bottom of one beam falling into the mud. 
2. The existing foundation columns did not provide an adequate foundation for a new floor system due to corrosion and potential code issues related to seismic loadings. (The term column, when referring to the existing foundation, is a simplification. The vertical component is either a concrete pile or a combination of a concrete column, a pile-cap and a group of piles. Most of this vertical component is embedded in the ground and is not accessible. The visible portion is either the top of a continuous pile or a column that extends down to a pile-cap that is likely supported by a group of timber piles.)

3. The existing columns were built with inferior materials. The concrete was built with river rock that has a compressive strength of 3,000 psi and the reinforcing steel has a tensile strength of approximately $30 \mathrm{ksi}$. Today, due to code issues and higher quality materials, angular aggregate and concrete mixes with typical strengths of 5,000 psi or higher are used for vertical members, and reinforcing steel with a tensile strength of 60 ksi or higher is used.

4. The existing columns were built with inferior design knowledge. For example, the confining steel in the existing column exceeds the current maximum spacing. New codes increased this confinement steel spacing to correct for non-ductile column failures identified through forensic studies of failed columns from seismic events over the last 40 years. These existing columns were built before this knowledge was available. Upgrading these deficiencies is impractical, especially when one considers that most of the structure is below water and embedded in the soil.

5. If the original beams were built to a live load limit of $250 \mathrm{psf}$, then the existing columns were probably also designed for this load. It is unlikely the existing columns were built 2-3 times stronger than originally required.

6. Building 301 and 303 have the building columns supported on the concrete beam and column system supporting the floor. Building 302, however, has most of the building columns supported on a pile system separate from the floor foundation. These separate supports are groups of 2 or 3 gunite coated timber piles supporting a concrete pile cap with the building column resting on a concrete pedestal on top of the pile cap. The gunite coating stops approximately 1 -foot above the mud line. Between the gunite coating and the mud line, the timber piles are heavily deteriorated. One pile in a group was found to have a diameter roughly the size of a baseball bat rather than the original 16-inch diameter pile.

7. A test program for 3 existing columns will test less than $1 \%$ of the existing columns. It is unlikely that all columns "aged" the same over fifty years. Thus a significant risk for unknown conditions will remain after a foundation test program.

8. The evaluations from the investigation indicate significant difficulties and costs associated with upgrading the current system to a status that would provide a safe load carrying capability by today's codes and industry standards.

As a result of these findings, the recommendation was for a new foundation system for any new structure to be constructed at the location of buildings 301, 302 and 303 . The existing foundation system under buildings 301,302 or 303 would not provide for a good foundation system for future structural systems. Also, it was concluded that additional testing of the existing foundations would not change these findings; therefore it was not recommended to proceed with the phase II testing of the foundations. 


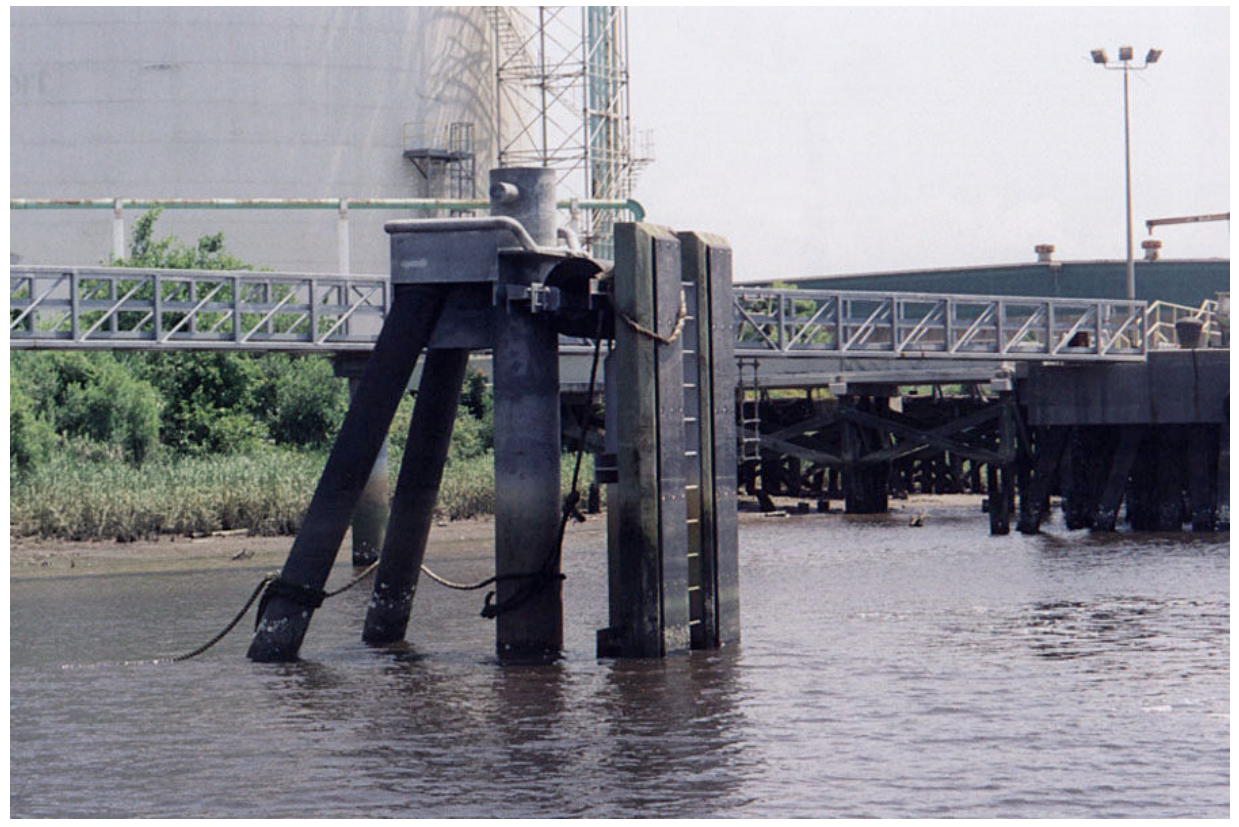

Breasting and Mooring Dolphin in Georgetown, South Carolina. This project required an energy evaluation of ship impact forces to determine the design forces, and the design of the structure to transfer 50-tons of horizontal force into soils consisting of limestone over silt.

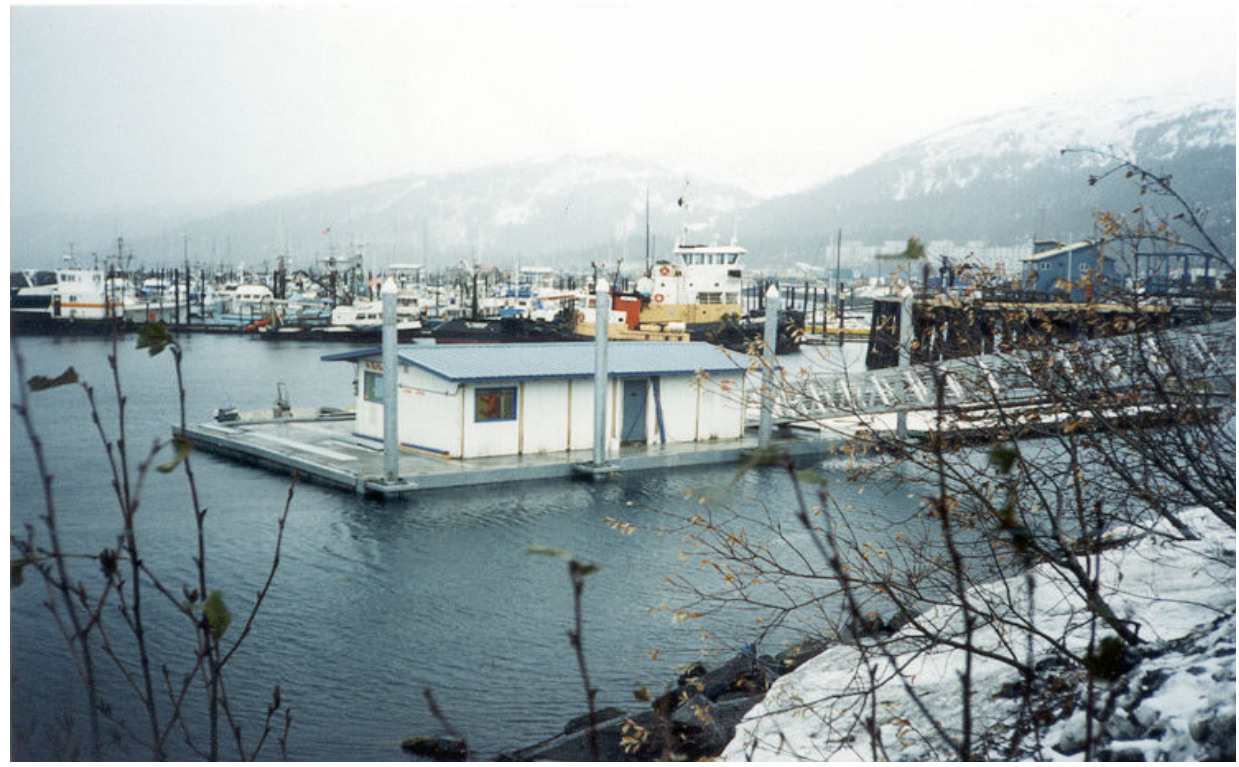

This 40 -foot by 60 -foot floating concrete fuel dock is located in Whittier, Alaska. The project involved wave forces, movement due to $30+$ foot tide changes, buoyancy calculations, as well as concrete design, pile design, aluminum gangway design and the design of fuel lines, water lines, and power. 


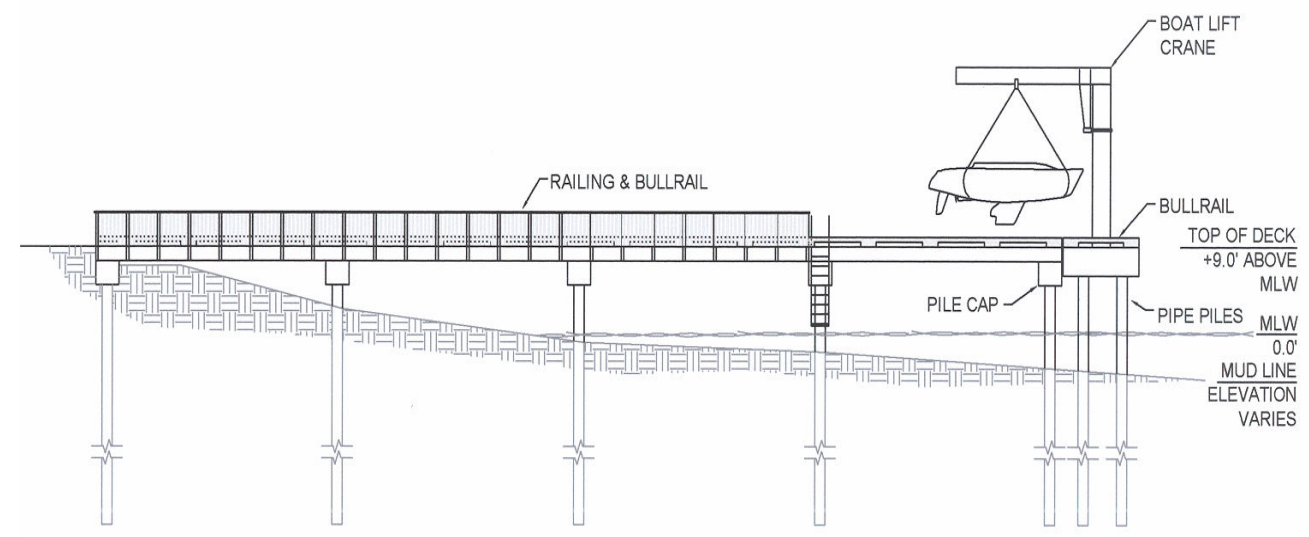

This fixed pier is located in Charleston, South Carolina. The design allowed launching of sailboats at low tide. This involved light vehicular loading, crane evaluation and loading, pile foundation design in Charleston's "Cooper Marl", and alignment with the currents, sedimentation concerns and prevailing winds.

\section{References}

1. ABET, ABET 2004-2005 Criteria for Accrediting Engineering Programs, Accreditation Board for Engineering and Technology, Baltimore, MD.

Author Information

ROBERT E. DULLANTY, SR.

Mr. Dullanty, PE is a Principal and Senior Structural Engineer in the Firm of Schneider \& Associates, Inc. in Charleston, SC. A graduate of the University of Washington, Mr. Dullanty specializes in Marine Structures and is comfortable in environments as diverse as the Alaskan Tundra to the balmy climate of South Carolina and Florida. After leaving the South Carolina State Ports Authority, Mr. Dullanty started his own engineering firm and in the summer of 2004 merged with the noted Forensic Architect, Kenneth G. Schneider, to form Schneider and Associates. 